\title{
WPS3961
}

\section{Global Redistribution of Income}

François Bourguignon

Victoria Levin

David Rosenblatt

The World Bank

\begin{abstract}
Summary:
The actual distribution of world income across countries is extremely unequal, much higher than the within country inequality faced by most countries. The question studied in this paper is: how do international policies on aid, trade and factor movements affect the international distribution of income?

To begin to answer this question, we calculate the impact by decile of the actual level of aid flows and the effect on potential income of merchandise trade restrictions by high-income countries. We find that aid's distributional impact is equality enhancing; while it is extremely small in terms of changes in standard inequality measures, it is of some importance for the lowest decile of the world's income distribution. We also find that some of this impact is counteracted by lost potential income in the lower deciles from merchandise trade barriers imposed by high-income countries. In brief, there is a contradiction in international policies where aid's equality-enhancing effect is somewhat offset by protectionism. We also discuss some of the analytical difficulties with extending this analysis of redistribution to other forms of international factor flows - more specifically, migrant worker and profit remittances.
\end{abstract}

The analysis presented here is partial and static and ignores within country distribution. As such, we suggest that future research should explore the distributional consequences of the broader general equilibrium effects, dynamic effects, and externalities associated with aid, trade, and factor flows. Future research should also analyze the within country distributional impacts of international policies.

World Bank Policy Research Working Paper 3961, July 2006

The Policy Research Working Paper Series disseminates the findings of work in progress to encourage the exchange of ideas about development issues. An objective of the series is to get the findings out quickly, even if the presentations are less than fully polished. The papers carry the names of the authors and should be cited accordingly. The findings, interpretations, and conclusions expressed in this paper are entirely those of the authors. They do not necessarily represent the view of the World Bank, its Executive Directors, or the countries they represent. Policy Research Working Papers are available online at http://econ.worldbank.org. 


\section{Introduction}

There has been an active literature in recent years on the world distribution of income. Some discussions focus on the "inter-country" distribution of income; that is, a distribution where countries are weighted equally, with China having the same weight as Barbados (for example, see Jones 1997). Other studies, like Theil and Seale (1994), still treat countries as the unit of analysis, but weigh their influence on world income distribution by population size. In what follows, this method is said to refer to the "international” distribution of income. Still other papers, such as the latest World Development Report of the World Bank (World Bank 2005b), combine estimates of within country inequality with those of international inequality to arrive at a more complete picture of income distribution, referred to as the "global” distribution of income.

In this paper ${ }^{1}$, we focus on the international distribution of income, abstracting from the admittedly critical element of within country inequality, since the purpose of our study does not allow us to take satisfactory account of the latter component of global inequality. ${ }^{2}$ Practical reasons for overlooking within country inequality are twofold. First, the calculations are much simpler. In particular, we can abstain from the recent debate on whether weighted inequality measures should be based on household survey data or national accounts data (Sala-i-Martin 2002, Bhalla 2002 vs. Milanovic 2002, Ravallion 2001). Furthermore, it has been shown that international inequality accounted for approximately 60 percent of overall inequality across the world’s citizens as recently as 1992 (Bourguignon and Morrison 2002)

\footnotetext{
${ }^{1}$ Some of these results were presented at the World Bank’s Annual Bank Conference on Development Economics (ABCDE), Washington D.C., May 3rd, 2004 and at the “ABCDE-Europe”, Brussels, May $10^{\text {th }} 2004$.

${ }^{2}$ Elsewhere (Bourguignon et al. 2004) we have shown that a more detailed analysis of individual countries' mobility along the income per capita scale provides an interesting perspective on the two seemingly contrary streams of the literature: the economic divergence literature, and the literature showing that inequality across countries has decreased over the recent period.
} 
and much more if one focuses on time changes rather than the absolute value of overall global inequality. The second reason to ignore within country inequality is that, in view of available data and methods for incidence analysis, there is practically no way to take into account the within country distributional impact of global redistribution mechanisms studied in this paper.

The objective of this paper is to analyze how direct transfers of aid as well as international policies that limit trade opportunities and possibly flows of labor and capital affect the international distribution of income. One of the international redistribution channels is the allocation of foreign aid by high-income donors to developing country recipients. To the extent that official development assistance (ODA) is in grant form or can be made equivalent to pure grants, these transfers can be thought of, in the short run, as pure redistribution of global income.

Trade is another area of international policy we consider in this paper. A successful implementation of multilateral trade liberalization via the Doha Development Round would increase the world's and many countries’ GDP, with interesting distributional consequences. While recognizing that most of the gains from multilateral trade liberalization would arise from the lowering of trade barriers between developing countries, we concentrate here on the redistribution effects of merchandise trade reform by high-income countries in order to compare these effects to those of ODA. Using World Bank’s computable general equilibrium (CGE) Linkage Model (van der Mensbrugghe 2005), we analyze the international redistribution of income that would result from fully liberalizing merchandise trade by highincome countries. 
Although politicians sometimes conflate the concepts of aid and worker or profit remittances, the latter have a much more complicated impact on the welfare of both the sending and the host countries, and therefore present a singular problem in our empirical analysis of global redistribution. We discuss the nature of these difficulties while also presenting some recent results, which point to the scale of redistribution that occurs through these flows.

The paper first describes the actual level of international inequality in 2002, which we will treat as a baseline in our further analysis. Then, we provide a brief summary of the theoretical literature on the transfer problem, as it relates to redistribution via aid and other flows. Empirical sections that follow discuss the actual impact of aid flows and the potential impact of merchandise trade reform in high-income countries. Finally, there is a discussion of the conceptual and empirical difficulties of conducting a similar analysis for both worker and profit remittances. We conclude with a discussion of some tentative policy implications of the quantitative results.

\section{The international distribution of income}

We used the World Bank’s World Development Indicators (WDI) 2004 for data on population and gross national income (GNI) in PPP-adjusted dollars. ${ }^{3}$ (See Appendix 3 for the list of countries.) The international distribution of income was obtained by assigning to every individual in the world the GNI per capita of the country he/she lives in. Figure 1 reveals details about the international distribution of income in 2002. In population-weighted terms, the poorest 40 percent of world population received just over 10 percent of world GNI,

\footnotetext{
${ }^{3}$ Drawing on the data used in Bourguignon et al. (2004), we deflated the GNI, PPP series to 1995 prices using the implicit United States GDP deflator found in WDI
} 
while the richest 20 percent commanded more than 60 percent of global national income. If we compare the two extremes, the ratio of the top vintile's GNI per capita to the bottom decile’s GNI per capita is 37 to 1 . The population-weighted Gini coefficient of international inequality in 2002 was 53.8, a value that is slightly below inequality in the most inegalitarian countries in the world, such as Nicaragua (55.1), Brazil (58.5) (World Bank 2004b) or South Africa (58) (Hoogeveen and Ozler 2004). ${ }^{4}$ It is important to remember that, as described above, our measure of international inequality does not take into consideration within country inequality; hence, “true” global inequality is much higher than what we have described here. Thus, if the world were a single country, it would be one of the most unequal countries in the world.

Figure 1: 2002 International Distribution of GNI per capita (1995 PPP Dollars)

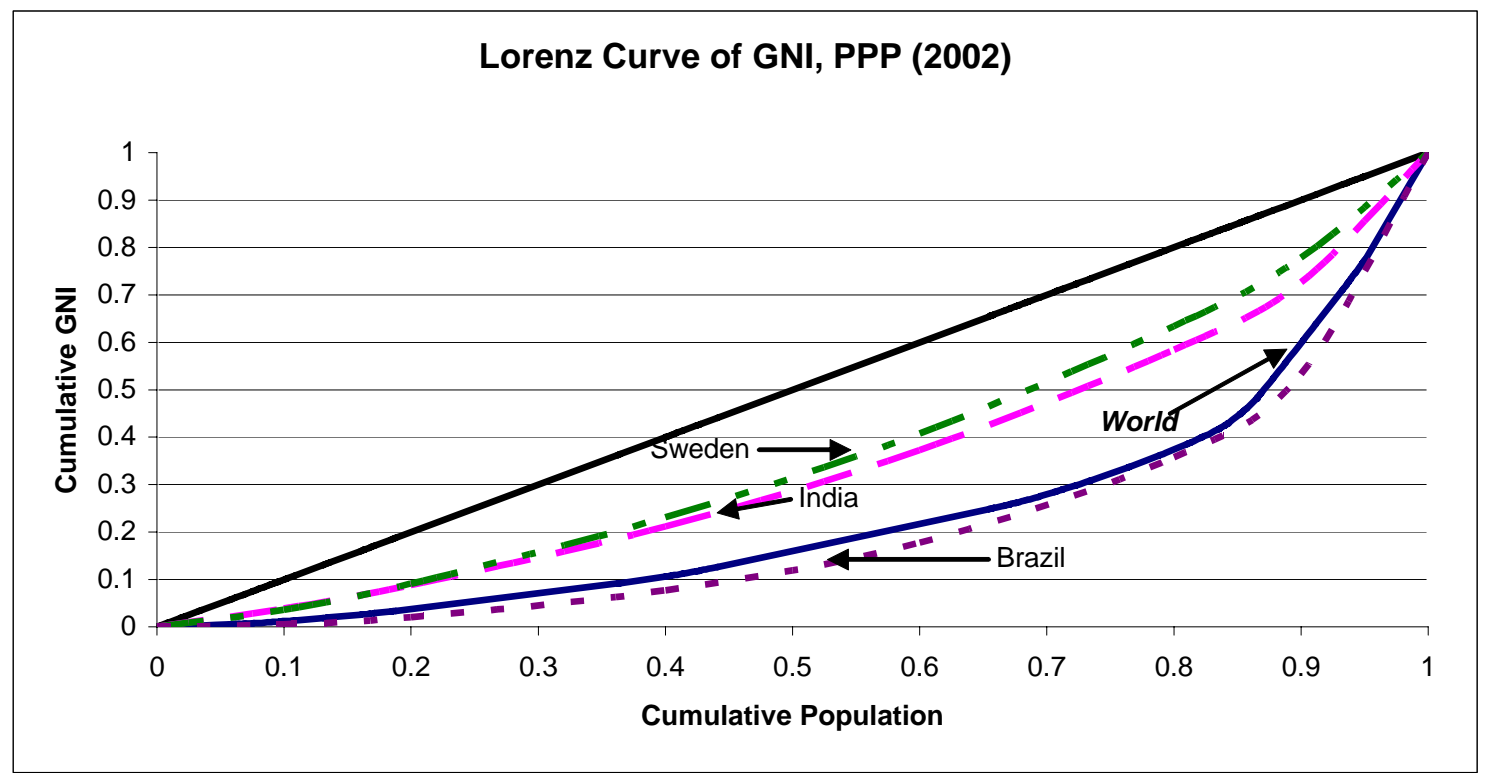

Source: Authors' estimates based on data from World Bank (2004b). Country-specific curves are smoothed curves based on deciles information.

As high as international inequality was in 2002, it appeared even greater in the two preceding decades, as measured by standard inequality indices. Bourguignon et al. (2004)

\footnotetext{
${ }^{4}$ Hoogeveen and Ozler (2004) use consumption Gini for South Africa, but presumably, income Gini would be even higher.
} 
analyze the different conclusions reached by studies of trends in international inequality and economic divergence. If one takes an anonymous view to who is in the various deciles of the world distribution and weighs countries by their population size, then the impressive growth of populous states like China and India in the last two decades serves as a powerful equalizing force for the international distribution of income. However, if one tracks mobility of countries' citizens through time, the trend is less unambiguous since many countries, mostly in Africa, had negative growth rates during that period. This ambiguity is similar to the difference observed between international and inter-country inequality. If one weighs countries equally, the impact of China's or India's growth, which has pulled millions of people out of poverty, is reduced to a single observation, and thus inter-country inequality is found to be rising not falling. ${ }^{5}$ Thus, Bourguignon et al. (2004) conclude that there was no Pareto improvement in the international distribution of income in 1980 to 2002, and the conclusions about rising or falling international inequality are rooted more in value judgments than straight data.

\section{Forms of international redistribution}

Without a global government, redistribution policies across countries are decided in a decentralized manner by national governments, individual citizens and firms. Redistribution of income takes place through a variety of channels, and there are numerous ways to account for the impact and the international policies that affect them. The simplest and most direct instrument of international income redistribution is official development assistance (ODA). ODA flows are a part of a recipient country's gross national income, and one can simply deduct these flows from actual GNI to determine the static effect of aid as an instrument of

\footnotetext{
${ }^{5}$ For an in-depth discussion of the evolution of inter-country and international inequality see Milanovic (2005)
} 
income redistribution; similarly, since donor’s GNI is calculated after ODA disbursements, one would simply add the ODA provided by a donor back to the donor's GNI to obtain the counterfactual.

By treating ODA as simple income transfers, we ignore the effects it may have on donor and recipient economies. Even before considering distributional impacts within countries or externalities — such as knowledge transfer that occur with aid — these effects may be subtle. There is a substantial theoretical literature on the general equilibrium effects of transfer flows between countries, starting with the early papers on German war reparations — aid "in reverse," one might say — focusing on how changes in the terms-of-trade due to the transfer could impact the transfer's real value. ${ }^{6}$ In the related macroeconomic literature, the focus has been on real exchange rate appreciation, and the concern that aid may lead to "Dutch disease" type effects that inhibit the export and the import-competing sector (Corden and Neary 1982).

Beyond the static general equilibrium effects, a more thorough understanding of aid's effect would include the dynamic impact of aid on relative growth rates of countries. A voluminous empirical literature estimating the impact of aid on growth has developed in recent years (for an overview, see Clemens et al. 2004). The regression results emerging from these studies often contradict each other, with no real consensus emerging at the present time; this makes it difficult to estimate with any degree of precision the impact of aid on growth of developing countries, and through growth, on the international distribution of income.

\footnotetext{
${ }^{6}$ Early formalized contributions include Samuelson (1952, 1954) or (Bhagwati et al. 1983) for more than two countries. More recent models have focused on the small-country setting (Yano and Nugent, 1999).
} 
However, we do acknowledge that these dynamic impacts are likely to be significant, and perhaps, much larger than the static impacts discussed in this paper. ${ }^{7}$

In addition to a direct form of redistribution via aid, there are more indirect instruments. The flows of goods and services, capital, labor, and knowledge all have impacts on the income of the world's countries and citizens. Of course, it is not these flows per se that directly contribute to redistributing income internationally since most of them have their counterpart. For instance, the flow of exports from country $i$ to country $j$ cannot be considered as an income transfer from $j$ to $i$ since the foregone consumption of $j$ must be taken into account — or equivalently the compensating import flows from all countries to $j$. Likewise, private capital flows from country $i$ to country $j$ have a counterpart, which are the profits repatriated by or the debt service to country $j$. If international markets were working fully competitively, these flows would not involve any sacrifice by one country for the benefit of another, unlike untied aid. In effect, the international redistribution behind those flows lies in the market imperfections that are under the control of the various nations and prevent more or different flows to take place and some countries to obtain all the benefit they could have with unrestricted flows of inputs and outputs. Protection of agricultural markets by rich countries, for example, contributes to lowering the international price of agricultural commodities, thereby inflicting a penalty on exporters or potential exporters. This is where international redistribution that is somewhat comparable to aid takes place, except unlike in the case of aid, it is not a zero-sum game. Likewise, restrictions on migration by some countries prevent flows of labor from taking place, and it is those restrictions that reduce, generally asymmetrically, the benefits of international labor flows for sending and host

\footnotetext{
${ }^{7}$ Appendix 1 presents an overview of this literature and a simulation of the dynamic impacts based on the results of one of the more prominent papers in the literature.
} 
countries. The challenge then is to estimate the income equivalent of welfare changes due to the current asymmetric barriers to the flows of goods, services, and factors, or the welfare impact of changing the existing barriers.

In this paper, we concentrate on the impact of trade liberalization by high-income countries on all countries' national incomes and the resulting effect on the international distribution of income. Removal of trade barriers by a group of countries could raise the income of the world as a whole, so trade liberalization clearly is positive-sum game. However, there may be winners and losers and, even in case there are only winners, some countries may gain more or less than others during the process of liberalization. Below, for simplicity's sake, we restrict our attention to the static gains from liberalization of trade in goods, and we continue to measure the redistributive impact solely through relative GNI per capita of countries.

Throughout the following sections, we will essentially focus on the static impacts of aid and trade liberalization. It turns out that there are difficult conceptual and empirical issues that make even this static impact analysis difficult for the examination of international redistribution taking place through national restrictions to migration or capital flows. Also, we recognize that important distributional impacts might be tied to the dynamic impacts of these flows. Many questions, like how capital flows or migration affect potential GDP growth, or how aid affects capital accumulation and economic growth, are critical to a more complete understanding of global distribution and redistribution but lie outside the scope of this paper. ${ }^{8}$

\footnotetext{
${ }^{8}$ We recognize that technical knowledge may be one of the most important economic flows affecting the world redistribution of income; however, this flow is particularly difficult to model and measure, and as such, it is beyond the scope of the exploratory analysis of this paper.
} 


\section{International redistribution through aid}

To evaluate the static impact that actual aid flows have on international income inequality, we conducted a simple exercise, treating grant aid flows and the grant element of concessional loans as direct income transfers from donor countries to developing countries. In doing so, we also assumed that all individuals within the country benefit equally from this transfer in the same way they were assumed to share equally the GNI. Since gross national income includes aid transfers as an accounting concept, the exercise consisted of subtracting out aid flows received by the beneficiary countries and adding the value of those flows back to donors' GNI. The OECD/DAC database (DAC 2004) allowed us to compile a dataset of different types of aid flows by donor-recipient pairs.

The most straightforward type of aid is bilateral grants, which are given by a donor country to a recipient country with no expectations of repayment. ${ }^{9}$ To these flows, we added the grant-equivalents of concessional lending, received by developing countries from bilateral donors. We calculated the grant-equivalents of bilateral net concessional lending using each donor's average grant element of ODA loans over the 1995-2002 period, based on annual grant element data from OECD’s Development Cooperation Reports (OECD 1998-2002). ${ }^{10}$

To take into account bilateral contributions to multilateral agencies as well as multilateral agencies' distribution of aid to developing countries, we used the data from

\footnotetext{
${ }^{9}$ For each of the flows (bilateral grants, bilateral loans, and imputed multilateral contributions), we have distributed "unspecified" and "unallocated" aid (listed as a regional aggregate) back to the region's members, using a pro rata calculation based on specified donor-recipient flows.

${ }^{10}$ Some DAC donors (Denmark and Switzerland), which had concessional loans in 2002, did not have the data on concessionality of these loans in the Development Cooperation Reports. For these donors, we used the average of DAC donors' grant element of ODA loans. Non-DAC bilateral donors (Czech Republic, Hungary, Iceland, South Korea, Latvia, Lithuania, Poland, Slovak Republic, and Turkey) do not report their loans individually, so OECD/DAC cannot calculate the concessionality of these loans. Since non-DAC bilateral donors were only recently emerging-market economies themselves, we assume that their lending is least concessional, and we assign a zero grant element to their concessional loans. We thank Ms. Yasmin Ahmad in OECD/DAC who helped us to gather the data on grant elements and explained to us the intricacies behind these numbers.
} 
OECD/DAC on the imputed multilateral contribution. ${ }^{11}$ Since multilateral agencies have a wide range of lending concessionality (from IMF's 25-30\% to UN agencies' 100\%) and since it would be a very data-intensive exercise to try to obtain grant elements for each of our multilateral donors, we performed several sensitivity tests with respect to the grant equivalence of the imputed multilateral component of the aid flows, assuming that this grant element was, in turn, 50 / 65 / 80 percent. $^{12}$ These tests showed that final results were marginally sensitive to the share of that grant element. The total amount of grant-equivalent aid in current US\$ in 2002 used for the simulation is 53.6 / 56.2 / 58.8 billion, depending on the grant element of imputed multilateral contribution. ${ }^{13}$

A second measurement issue is the treatment of debt relief in the aid data. Grants for debt relief count for the whole future flow of debt service saved - in 2002, debt relief consisting of debt forgiveness grants and rescheduled debt made up almost $10 \%$ of total net $\mathrm{ODA}^{14}$; however, in our calculations we are trying to estimate the impact of an annual flow of aid. As a result, we examined data on the annual debt service in 2001-2002 as a fraction of the stock of official debt outstanding. It turns out that this ratio is roughly 4 percent (World Bank 2005a).

\footnotetext{
${ }^{11}$ OECD/DAC calculates the imputed multilateral contribution by distributing each DAC donor country's contribution to multilateral agencies to recipient countries, using pro rata calculation of the percentage the multilateral agency gives in grants or concessional loans to each particular recipient. These figures are then added across multilateral agencies that receive contributions from this particular DAC donor country to arrive at a donor-recipient "imputed multilateral" contribution.

${ }^{12}$ Results of these sensitivity exercises are available from the authors upon request.

${ }^{13}$ To make these data comparable to our base of actual GNI per capita, we deflated these aid volumes to 1995 dollars, using the same procedure as we had used for deflating GNI in Section II.

${ }^{14}$ As suggested by OECD/DAC, we included (negative) offsetting entries for debt relief in this calculation to avoid double-counting (DCD/DAC 2002).
} 
A third issue concerns aid disbursed as technical cooperation. It usually does not go through the recipient country's budget, and as such does not have a real effect on the recipient's GNI. We have netted it out in two of the scenarios presented below.

Finally, an important issue that arises in measuring the redistributive effect of aid is whether aid flows should be subtracted from countries' gross national incomes (expressed in PPP dollars) in dollar terms or in PPP dollars. If one converts the aid flows into PPP dollars, then the redistribution of aid is no longer zero-sum. ${ }^{15}$ Yet, it is shown in appendix 2 that this is a satisfactory way of proceeding if indeed welfare is measured by PPP-corrected GNI. General equilibrium effects of aid actually lead to a corrective term but that term is likely to be small.

In summary, there are three measurement issues for which we calculated various different scenarios. The first issue is the grant equivalence of imputed multilateral lending, the second issue is the inclusion of debt relief in the aid figures, and the third issue is whether technical cooperation should be included or excluded from this analysis.

To arrive at a range of values for the redistributive impact, we then took as a maximum value scenario as follows: 0.8 grant equivalent for concessional lending, aid flows measured in PPP dollars relative to PPP-corrected GNI per capita, zero discounting of debt relief so that the stock is counted as is reported to OECD, and technical cooperation not netted out. For a minimum distributive impact calculation, we lowered the grant equivalent of lending to 0.5 , and completely removed both debt relief and technical cooperation from the aid flows. Finally, for an intermediate calculation - and our preferred estimate — we used the 0.5 grant

\footnotetext{
${ }^{15}$ To convert aid in dollars to aid in PPP terms, we multiply the former by a ratio of GDP, PPP to GDP in dollars, all taken from WDI 2004.
} 
equivalent scenario for lending flows, and discounted debt relief by 96 percent (leaving the four percent average debt service flow) while still netting out all technical cooperation.

The table below presents inequality indices with (base case) and without aid flows for the year 2002, using the three scenarios described above. The difference between the minimum calculation and the intermediate calculation is so small that we have chosen not to include it in the table or figure below. Figure 2 shows the impact of aid on the mean GNI per decile of the international distribution.

Table 1. Impact of aid flows, 2002

\begin{tabular}{|c|c|c|c|c|c|c|c|}
\hline \multirow{2}{*}{$\begin{array}{l}\text { Case (all income inequality measures } \\
\text { population -weighted) }\end{array}$} & \multirow[b]{2}{*}{ \# of obs. } & \multirow[t]{2}{*}{ Gini } & \multirow{2}{*}{$\begin{array}{l}\text { Theil } \\
\text { Entropy }\end{array}$} & \multirow{2}{*}{$\begin{array}{c}\text { Mean } \\
\text { Log } \\
\text { Dev }\end{array}$} & \multicolumn{3}{|c|}{ Atkinson } \\
\hline & & & & & $e=0.5$ & $e=2$ & $e=5$ \\
\hline Base (after aid) & 159 & 0.5380 & 0.5305 & 0.5316 & 0.2378 & 0.6187 & 0.8291 \\
\hline $\begin{array}{l}\text { "Maximum Scenario" (aid netted out) } \\
\text {-0.8 grant equivalent of imputed } \\
\text { multilateral } \\
\text {-All debt relief included } \\
\text {-All technical cooperation included }\end{array}$ & 159 & 0.5424 & 0.5391 & 0.5507 & 0.2427 & 0.6468 & 0.8805 \\
\hline $\begin{array}{l}\text { "Preferred Scenario" (aid netted out) } \\
\text {-0.5 grant equivalent of imputed } \\
\text { multilateral } \\
\text {-96 percent of debt relief deducted } \\
\text {-All technical cooperation deducted }\end{array}$ & 159 & 0.5404 & 0.5351 & 0.5415 & 0.2404 & 0.6319 & 0.8498 \\
\hline
\end{tabular}

Source: Authors' estimates based on data from World Bank (2004b) and DAC (2004) database on aid flows.

The impact of aid on international inequality is extremely small when one is using inequality measures sensitive to high and middle incomes. It is slightly bigger, but remains very limited for inequality measures giving more weight to the poor - i.e. the mean logarithmic deviation or the Atkinson measure with high inequality aversion, $e$. The explanation of this result is given by Figure 2. In the maximum scenario, aid produces a 
change in the poorest decile's welfare equal to 14 percent and negligible proportions for intermediate deciles. Of course, it represents a loss for the top deciles approximately equal to the share of ODA in the GNI of donor countries, that is, approximately 0.25 percent in $2002{ }^{16}$ As a consequence, only international inequality indices which are very sensitive to the relative income of the poor are significantly affected by the international redistribution through aid. The Gini coefficient increases by .44 percentage point, from its base case value of 0.538 , when aid is netted out. By contrast, the mean logarithmic deviation increases by almost 2 percentage point, from the base case value of 0.5316 .

Interestingly, nearly half the .44 percentage point reduction in the Gini coefficient is removed when technical cooperation and debt relief are deducted. This is not surprising given that nearly half of all grant aid in 2002 was in the form of either technical cooperation or debt relief. In figure 2, we see that nearly half the impact on mean GNI per capita in the first decile is also eliminated. Nevertheless, the increase of nearly 8 percent for the bottom decile is still fairly substantial.

The preceding results should not be over-emphasized, however. Even when focusing on the change in the welfare of the poorest decile or considering poverty sensitive inequality measures, estimates of the effect of redistribution through aid are dwarfed when compared to the extent of redistribution that takes place within countries equipped with effective redistribution schemes. ${ }^{17}$ Thus, the international redistribution that is taking place in the

\footnotetext{
${ }^{16}$ Note that there is little difference between the three scenarios for the rich countries.

${ }^{17}$ By comparison, tax and transfer programs in the United Kingdom lower the Gini coefficient from 0.53 to 0.40 - a full fifteen percent reduction-during the 1990s (Lakin 2001). In France, the system of tax and transfers raises the final income (per adult equivalent) of the poorest 20 per cent by nearly 70 percent, several other European countries having an even higher degree of overall redistribution (Bourguignon 1998). In the developing country context, Mexico's public expenditures (including in-kind services) decrease the Gini from 0.48 to 0.39 , an $18 \%$ reduction in inequality (World Bank 2004a). Even though these various studies adopt different definitions of redistribution and are not strictly comparable, they show how important the scope for redistribution may be at the national level..
} 
world through aid appears limited both in absolute terms and in comparison with what may be observed in single high-income and even middle-income countries.

Of course, the preceding conclusion in no way means that aid is ineffective. If the assumption of an equal distribution of aid benefits within the population is accepted, then an 8 to 15 percent increase in the real income of the poorest is not negligible. Figure 2 also reveals that, under the assumption that aid income is equally shared within countries aid is very effectively targeted towards the poorest of the poor. Approximately 41 percent of all the aid made available by donors (measured in PPP dollars, and including technical cooperation and debt relief) goes to the poorest decile, and 25 percent is allocated to the second decile. ${ }^{18}$

\section{Figure 2: Per capita PPP GNI, Percent Impact of Aid, By Decile}

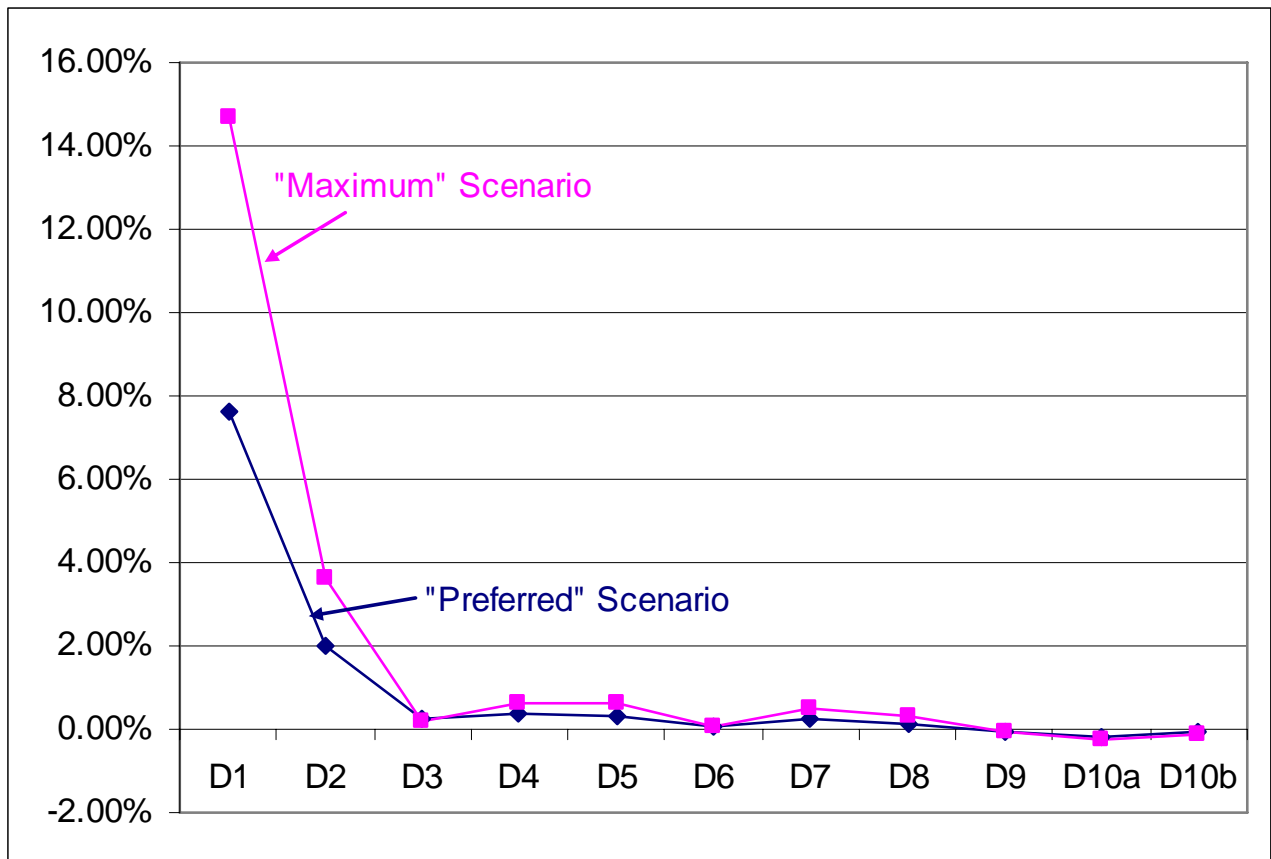

Source: Authors' calculations based on data from World Bank (2004b) and aid flow data from DAC (2004). See text for description of the scenarios.

\footnotetext{
${ }^{18}$ We conducted a similar analysis for aid in 1985. The major difference in the results was that less aid was distributed to the bottom deciles and more aid to the middle deciles, suggesting that the targeting of aid to the poorest countries has improved since the end of the Cold War.
} 


\section{Redistribution through trade protection}

To analyze the impact of existing trade protection on international inequality, we used the World Bank Linkage Model. ${ }^{19}$ This model calculates the long-term steady-state gains from complete liberalization of trade in goods around the world simulated to take full effect by 2010. These gains are expressed as the difference in welfare in 2015 relative to the baseline scenario of no additional trade liberalization. In our exercise, we are discounting these future gains to 2002, our baseline year. Thus, when we refer to "lost potential income from existing trade protection” or the "benefit from future trade liberalization,” we imply the steady-state gains calculated by the model.

The model works with 27 "country units,” some of which are individual countries and others are regional groupings of countries. (The details of the country groupings are presented in Appendix 3.) To remain consistent with our initial framework, it has been assumed that all countries within a country group were affected in the same way by trade liberalization. In order to capture the impact of rich countries’ policies on the developing countries, we used a scenario modeled by van der Mensbrugghe (2005) whereby only highincome countries remove all tariffs on merchandise trade and all domestic agricultural support. $^{20}$ By estimating the difference with the benchmark situation, these simulations inform us on the impact of existing protection imposed on developing countries by highincome countries. The model provides results for the static changes in GDP evaluated in PPP terms and changes in real household income; here, we concentrate on changes in real household income as a more appropriate welfare measure. Economies of scale, productivity

\footnotetext{
${ }^{19}$ Our gratitude to Dominique van der Mensbrugghe for providing the results and advising us on this exercise. Technical details on the model are to be found in van der Mensbrugghe (2005).

${ }^{20}$ See World Bank (2004a) for details.
} 
gains, or other dynamic effects from trade are not reflected in this model. In addition, liberalization of services is not considered. We applied the relative changes in real household income to PPP-corrected GNI — assuming that GNI follows the same evolution as real household income — using 2001 as the base year, similar to the Linkage model.

An important point to note in this exercise is that trade liberalization is increasing the efficiency of the world economy, so that the redistribution that it entails is a positive-sum game. However, this is not for the same reason as for aid. In the case of aid, the overall gain was coming from transferring dollars to countries with lower costs of living. In the present case, the overall gain is the standard 'gain from trade'. In effect, the world average welfare increases by approximately 0.4 percent as a result of the liberalization policy.

In terms of inequality, the redistributive effects of high-income country protection in world trade are smaller in absolute value that those of aid. The Gini coefficient of the international distribution would be lower by 0.06 percent in the absence of protection. However, the poverty sensitive measure like the Atkinson index with high levels of inequality aversion show much less variation than in the case of aid, suggesting that the redistribution that would take place through liberalization is not exclusively towards the poorest in the world. 
Table 2. Simulations of Trade Reform

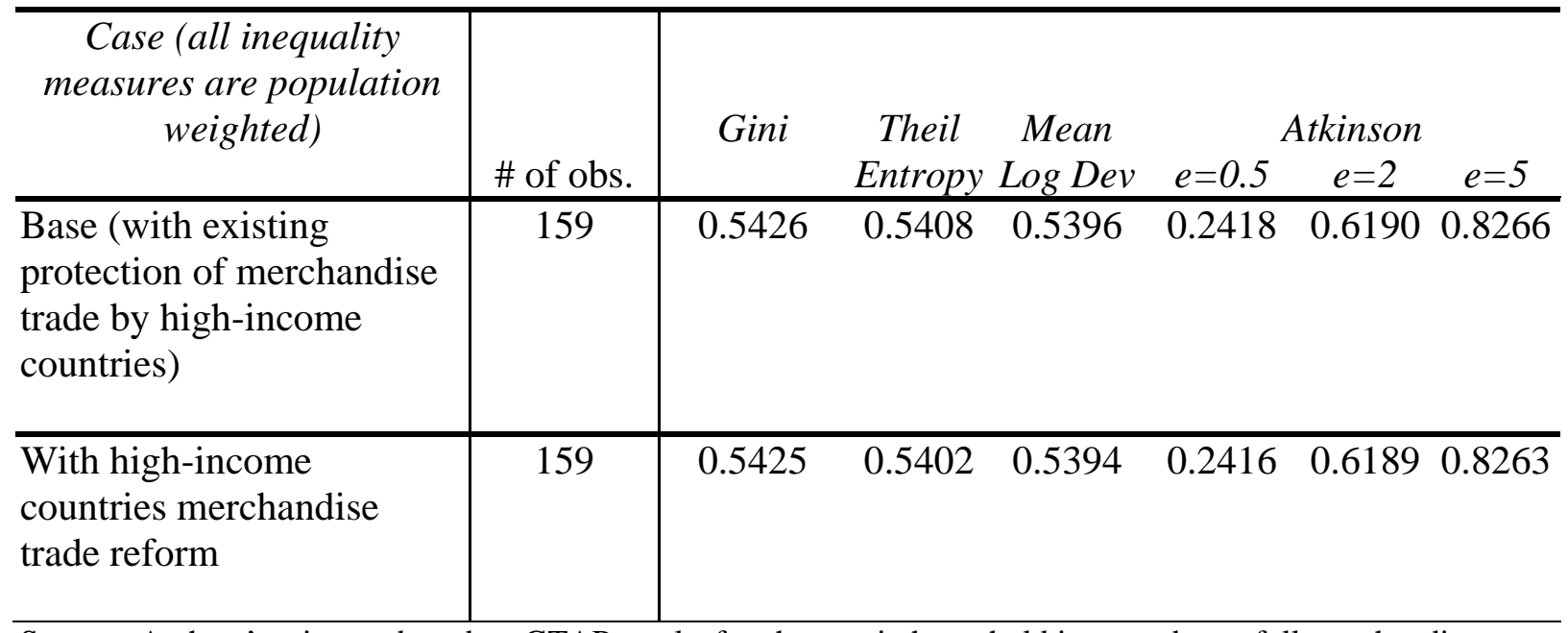

Source: Authors' estimates based on GTAP results for changes in household income due to full merchandise trade reform by high-income countries in 2001 (de Mensbrugghe 2005). The "Base" inequality measures here differ from Table 1, since the baseline year in the case of trade is 2001 (the year used by de Mensbrugghe 2005), while in the case of aid it is 2002.

The figure below presents the impact of high-income countries' trade liberalization in goods across deciles of world population. Efficiency gains imply that all deciles lose because of protection. However, what matters for inequality is who loses more or less than the world average, represented by the dotted line in Figure 2. As anticipated on the basis of inequality measures, we can see in Figure 3 that low- and middle-income deciles, especially deciles one (Sub-Saharan Africa), eight (China, Malaysia and Philippines, many Latin American and Caribbean countries, Turkey) and nine (Middle East and North Africa, Thailand, Brazil, and Russia) as well as the second-highest vintile (some EU-25 countries, Hong Kong and Singapore, Australia and New Zealand, Japan, Canada) benefit the most from merchandise trade reform in high-income countries, while the top vintile (USA and part of Canada) loses with respect to the average gain in the world economy but not in absolute terms (indeed, it still gains $0.02 \%$ ). Other relative losers include deciles 3, 5 and 6. In other words, trade liberalization in developed countries would benefit less those groups of people than average. 
The dynamic effects of trade liberalization might imply that the losses from protectionism are a multiple of the values displayed in Figure 3. To the extent that dynamic effects are similar across deciles, the losses from high-income country protectionism would still follow the pattern in the figure displayed below.

Figure 3: Effects of High Income Country Protectionism

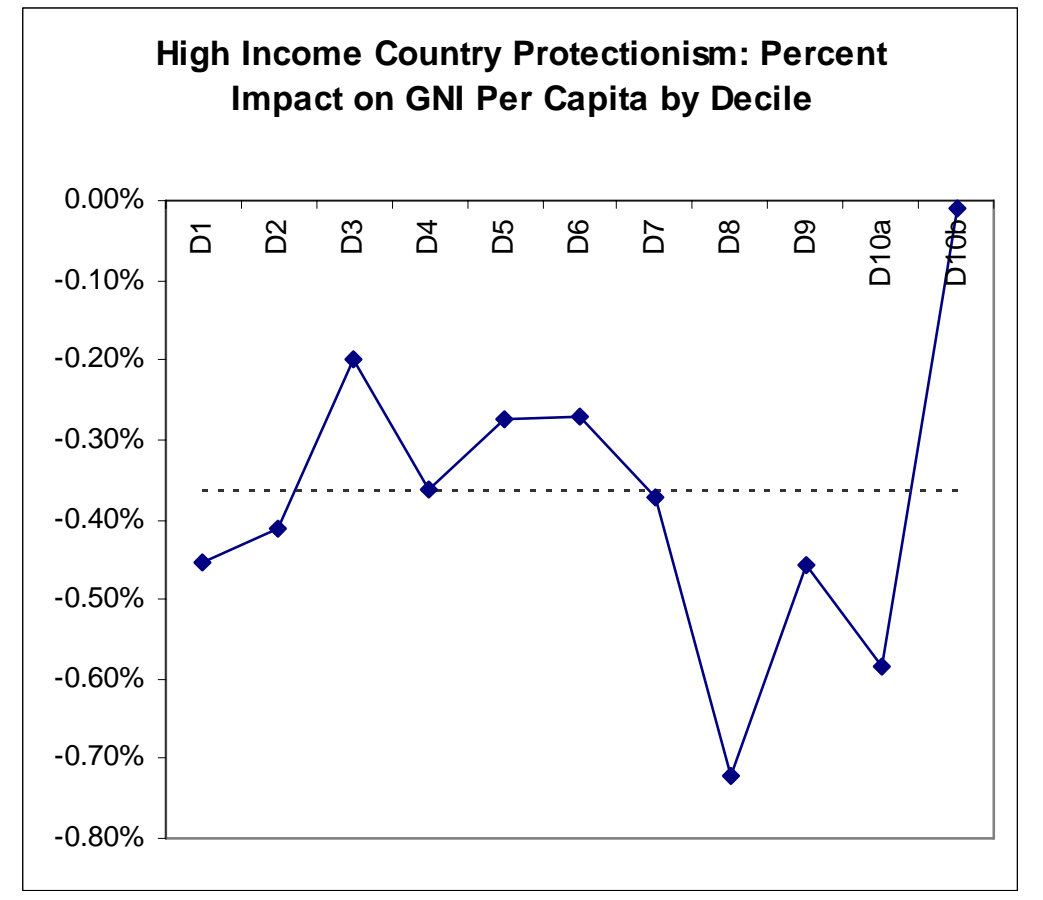

Note: No productivity enhancement. Change in real household income from the model. Dotted line represents aggregate world impact. Source: The Linkage Model (van der Mensbrugghe 2005).

It is interesting to discuss the combined impacts of the two sources of international redistribution discussed above - aid and trade protection. To do so, we compare the redistribution effected via existing aid levels versus the lost income caused by the existing barriers to trade in rich countries. In this way, we have a rough approximation of the impact of two international policies (aid and trade) on global distribution of income. For the bottom deciles, part of the gains from aid is negated by the detrimental impact of trade barriers via lost income, but the overall effect remains positive. For upper-middle income deciles, the lost 
trade income cancels out the small income transfers received as aid. Note that the comparisons should not be taken literally, since the base years of the two simulations differ: for aid, the base year is 2002, while for trade it is 2001 .

To sum up, the analysis of the redistribution that takes place through aid and through protection leads to both positive and negative conclusions. The positive conclusion is that the poorest one or two deciles of the international distribution see their welfare increased, although in a limited way and with some ambiguity in the magnitude of change, since this depends on whether debt relief and technical cooperation are included or not. Overall, the richest vintile of the international distribution - the richest countries - are neither losers nor gainers in this redistribution game: the impacts are just too small relative to GNI per capita in these countries.

As mentioned previously, we have not been taking into account the dynamic effects of aid and trade liberalization on growth in these exercises. A way of proceeding would be to project GNI in the future based on the assumptions on how aid and trade protection may affect rates of growth (Appendix 1 extends the analysis of aid effects on inequality, based on the Collier-Dollar model of aid-growth relationship). If those effects are proportional to the flows observed in 2002, which themselves correspond to some kind of a steady state, no big change will be obtained in terms of redistribution with respect to what we described above. Things would be different if there were a lot of heterogeneity in the way aid and trade protection affect countries' rates of growth, but the literature is much too imprecise to go in that direction. 


\section{Remittances: conceptual and empirical difficulties}

International factor income flows, or remittances, a priori, look very much like international income transfers, and in particular public and private aid. In particular, they look very much like a zero-sum game in which some countries appear as net transferors and others as net transferees. This similarity between factor income flows and international transfers makes it very tempting to consider them on the same footing as other types of "development flows.” In effect, more and more frequently we hear top politicians referring to migrant worker remittances as contributing to the development of the countries of origin of migrants (Powell 2002), which in policymakers' minds may be some kind of substitute or complement to more traditional aid flows.

Such an approach is clearly flawed. There is an enormous difference between factor income flows and international income transfers. It is that the former are the counterpart of the delivery of a service, whereas the latter simply have no such counterpart. Migrant workers perform a job in host countries and remittances must be seen as a part of the payment they receive for their activity that is being sent back home. Likewise, profit repatriation has to be seen as part of the return on the foreign direct investment that settled in a country over the past, the complement being undistributed and reinvested profits. There is no such direct economic counterpart to Official Development Assistance - even though aid is sometimes "tied" in one way or another - or in private development flows handled by NGOs. The fact that it is often difficult to distinguish statistically private "transfers" from "migrant worker remittances” should not lead to a conceptual confusion between those two types of flows.

The preceding argument does not mean that no international redistribution is taking place through labor migration and capital flows. It simply emphasizes that international wage 
or profit remittances and interest payments are not the right indicators of that redistribution. In effect, the problem is very much the same as that of international trade. As shown above, the redistribution taking place through international trade cannot be gauged by tracking the payments made for the imports and exports of a specific commodity. Nor would it make sense to consider that trade balances have anything to do with an income transfer. In both cases, there is, again, a clear counterpart. In the case of exports or countries with a positive trade balance, it is the claim that is generated on goods produced by other countries. In the case of imports and negative trade balances, it is the claim that other countries are acquiring on home goods.

Yet, as seen in the previous section, some redistribution is taking place through international trade, or more exactly through the existence or the absence of impediments to trade. Exactly the same kind of argument may be made in the case of labor and capital movements. Welfare gains or losses associated with these movements can only be gauged by comparing them to a situation where those movements would be prohibited, or possibly the situation where they would be freed. If rich countries were to liberalize their immigration policies, accepting more migrant workers from poor countries, this could potentially increase welfare in both rich and poor countries, but presumably in different proportions. The extent of international redistribution that is taking place today through migration must thus be evaluated by comparing the present structure of barriers to migration to some benchmark situations, as for instance no migration or some arbitrary level of migration. Moving from the present situation to one of these two benchmarks implies changes in national welfare, which may somehow be considered as the redistribution impact of today's international migration 
regime. This is exactly the approach that was followed in the preceding section for international trade.

Following the example of trade, for instance, one method to evaluate the redistribution impact of labor migration would be to introduce barriers to migration in a model of the world economy and to see how the international allocation of production and consumption would be affected if those barriers were modified. This is a difficult exercise, which would require data on stocks of migrants in host countries by country of origin, the wage differential between countries, the cost of migration, and also some rather strong assumptions on migration behavior, and parameters that may determine the volume of immigration in host countries. In the absence of such a model both for labor and capital flows, and in view of the extremely imprecise data on both migration stocks and remittances, we have not pursued that direction here, leaving the issue of international redistribution through those two types of flows open to future research. $^{21}$

\section{Conclusions}

Although this paper is about international inequality, we know that the actual level of global inequality of income is extremely high - with a Gini coefficient between 0.64 (Milanovic 2005) and 0.66 (Bourguignon and Morrisson 2002). If this level of inequality were to exist within a single country, that country would probably experience substantial social strife. That this does not happen in the world simply means that, as of today, there is

\footnotetext{
${ }^{21}$ A recent simulation conducted for the Global Economic Prospects 2006 of the World Bank (World Bank, 2005c) uses a global Computable General Equilibrium model to estimate the impact on global income of an increase in migration equivalent to 3 percent of high-income countries' labor force. The simulations reveal an increase of 0.9 percent in global real income, adjusting for purchasing power parity, given the change in location of migrants' own consumption. In the simulation, most of the gains accrue to the new migrants themselves, while the only declines in real income are experienced by "old" migrants, i.e. the existing migrants prior to the increase in migration. We could not use these results in the framework developed in this paper because the assumption of identical income within all countries prevented to distinguish between nationals, old and new migrants.
} 
nothing like a global community. ${ }^{22}$ Therefore, a renewed emphasis on increased redistribution from aid, lowering economic barriers that are detrimental to the poor of the world, and renewed policy reforms to assure that aid and freer movements of factors and goods enhance growth prospects for low-income countries are urgently needed.

The current aid flows are small globally but can be large locally. They have a small impact on aggregate inequality indices, but more effect is revealed on a decile by decile basis. One discouraging result is that some of the favorable impact of aid is decimated by the negative impact of trade restrictions imposed by high-income countries on potential income in the developing world. In brief, there is a contradiction in the set of international policies on aid and trade, where the benevolent hand of aid is somewhat countered by the malevolent hand of protectionism.

The analysis presented in this paper should be considered a first approximation. It ignores, first of all, the important impact of policies on the within country distribution of income and how this affects the global distribution of income. In addition, this analysis only takes a preliminary look at some of the general equilibrium effects (in the case of trade) of international policies, and abstracts away from externalities associated with trade liberalization or movements of factors across international borders.

Finally, this paper treats redistribution as a static one-off phenomenon. Aid and trade reforms (as well as investment financed by remittance flows) can all have a strong impact on growth. As noted elsewhere (Bourguignon et al. 2004), growth needs to be revived in the

\footnotetext{
${ }^{22}$ Kopczuk et al (2005) assume a Bergson-Samuelson social welfare function to study the optimal degree of redistribution if the function is taken as border-neutral-i.e., a citizen's welfare weight is not a function of his or her nationality. The simulation shows that the optimal international income tax would result in vastly greater redistribution than exists in the world today. The simulations also show that existing aid levels is consistent with the typical US citizen valuing foreigners' well-being as $1 / 6$ as important as an American citizen and 1/2000 for the residents of the poorest countries in the world.
} 
stagnating economies of the bottom decile if recent trends toward lower international inequality - in population-weighted terms—are to continue. More research should be done on how aid, trade liberalization, and factor flows affect growth, and through it, the global distribution of income. 


\section{REFERENCES}

Bhagwati, Jagdish, Richard Brecher, and Tatsuo Hatta (1983). “The Generalized Theory of Transfer and Welfare: Bilateral Transfers in a Multilateral World.” American Economic Review 73(4), pp. 606-618. September.

Bhalla, Surjit S. (2002). Imagine There's No Country: Poverty, Inequality, and Growth in the Era of Globalization. Washington, DC: Institute for International Economics.

Bourguignon, François (2005). "Measuring the national and global welfare gains from aid.” Processed. The World Bank, Washington DC.

(1998). Fiscalité et redistribution. Paris: La Documentation française.

Bourguignon, François, Victoria Levin, and David Rosenblatt (2004). “Declining international inequality and economic divergence: Reviewing the evidence through different lenses.” Economie Internationale 100(4), pp.13-25.

Bourguignon, François, and Christian Morrisson (2002). "Inequality Among World Citizens: 1890-1992.” American Economic Review 92(4), pp. 727-744. September.

Burnside, Craig, and David Dollar (2000). “Aid, Policies, and Growth.” American Economic Review 90(4), pp. 847-68. September.

Clemens, Michael, Steven Radelet, and Rikhil Bhavnani (2004). “Counting Chickens When They Hatch: The Short Term Effect of Aid on Growth.” CGD Working Paper 44. July.

Collier, Paul, and David Dollar (2002). “Aid Allocation and Poverty Reduction,” European Economic Review 46(8), pp. 1475-1500. September

Corden, W Max, and J Peter Neary (1982). "Booming Sector and De-Industrialisation in a Small Open Economy.” Economic Journal 92(127), pp. 825-48.

Development Assistance Committee of OECD (DAC) (2004). International Development Statistics. Paris: OECD. Statistical online database.

Development Co-Operation Directorate / Development Assistance Committee (DCD/DAC) (2002). DAC Statistical Reporting Directives. Paris: OECD.

Dollar, David, and Victoria Levin (2004). “The Increasing Selectivity of Foreign Aid, 1984-2002.” World Bank Working Paper No. 3299. May. 
Dornbusch, Rudiger (1980). Open Economy Macroeconomics. New York: Basic Books.

Easterly, William, Ross Levine, and David Roodman (2003). "New Data, New Doubts: A Comment on Burnside and Dollar's ‘Aid, Policies, and Growth'.” NBER Working Paper 9846.

Hoogeveen, Johannes, and Berk Ozler (2004). "Not Separate, Not Equal: Poverty and Inequality in Post-Apartheid South Africa.” Unpublished manuscript.

Jones, Charles I. (1997). “On the Evolution of the World Income Distribution.” Journal of Economic Perspectives 11(3), pp. 19-36. Summer.

Kopczuk, Wojciech, Joel Slemrod and Shlomo Yitzhaki, 2005, "The limitations of decentralized world redistribution: An optimal taxation approach.” European Economic Review, 49, pp. 1051-1079.

Lakin, Caroline (2001). "The effects of taxes and benefits on household income, 19902000.” Economic Trends. No. 569.

Milanovic, Branko (2005). Worlds Apart: Measuring International and Global Inequality. Princeton, NJ: Princeton University Press.

Milanovic, Branko (2002). "True World Income Distribution, 1988 and 1993: First Calculation Based on Household Surveys Alone.” Economic Journal 112(476), pp. 51-92. January.

Organisation for Economic Co-operation and Development (OECD) (1998-2002). Development Co-operation Report. Paris: OECD.

Powell, Colin (2002). "Making Sustainable Development Work: Governance, Finance, and Public-Private Cooperation.” Remarks at State Department Conference, Meridian International Center, Washington, D.C.

Ravallion, Martin (2001). "Growth, Inequality, and Poverty: Looking Beyond Averages.” World Development 29(11), pp. 1803-1815.

Sala-i-Martin, Xavier (2002). "The World Distribution of Income (estimated from Individual Country Distributions).” NBER Working Paper 8933, May.

Samuelson, Paul A. (1952). "The Transfer Problem and Transport Costs: The Terms of Trade When Impediments are Absent.” Economic Journal 62(246), pp. 278-304. June.

Samuelson, Paul A. (1954). "The Transfer Problem and Transport Costs, II: Analysis of Effects of Trade Impediments.” Economic Journal 64(254), pp. 264-289. June. 
Theil, Henri, and James L. Seale, Jr. (1994). “The Geographic Distribution of World Income, 1950-1990.” De Economist 142(4), pp. 387-419. November.

van der Mensbrugghe, Dominique. (2005), “LINKAGE Technical Reference Document: Version 6.0.” Processed. The World Bank, Washington D.C.

World Bank (2004a). Mexico: Public Expenditure Review. Washington D.C.: The World Bank.

World Bank (2004b). World Development Indicators. Washington D.C.: The World Bank.

World Bank (2005a). Global Development Finance: Mobilizing Finance and Managing Vulnerability. Washington D.C.: The World Bank.

World Bank (2005b). World Development Report 2006: Equity and Development. Washington D.C.: The World Bank.

World Bank (2005c). Global Economic Prospects 2006: Economic Implications of Remittances and Migration. Washington D.C.: The World Bank.

Yano, Makoto, and Jeffrey B Nugent (1999). “Aid, nontraded goods, and the transfer paradox in small countries.” American Economic Review 89(3), pp.431-449. June. 


\section{Appendix 1: Dynamic Effects of Aid - Aid as Investment}

Section IV of the paper focused solely on the static impact of aid on the distribution on income between countries. There, we treated aid as a static, one-off mechanism for redistribution of current consumption. However, donor countries expect aid not just to increase consumption of recipient country citizens by the amount of ODA, but also to be invested in capital, which will enhance developing countries' growth in the future. In this appendix, we apply some of the results attained in the existing aid-growth literature to take a first cut at the potential dynamic redistribution impact of aid.

Driven by the donor community's desire to see aid contributing to growth and poverty reduction in developing countries, a vast literature emerged in the last decade exploring the connection between ODA and growth. Representing the whole spectrum of model specifications and estimation methods, the studies conducted so far support one of three quite different conclusions about the effect of aid on growth. ${ }^{23}$ First, there are studies, such as Clemens et al. 2004, which find aid always contributing to recipient countries' growth, albeit sometimes with diminishing returns . Other authors, most recently Easterly et al. (2003), reach the opposite conclusion that aid has at best, an insignificant, and at worst, a negative effect on growth. Finally, still other research on the same topic, as that conducted by Collier and Dollar (2002), yields conditional results, with the sign and magnitude of aid's effect on growth depending on certain features or characteristics of recipient countries, such as quality of their institutions and policies or vulnerability to shocks. This diversity of empirical results and the divergence of conclusions complicate our attempt to apply the findings of existing literature to an exercise assessing redistribution effects of aid as investment. If we use the studies finding a negative correlation between aid and growth, then we would see that aid increases international inequality of income. If, on the other hand, we focus on studies where aid is growth-enhancing, we will conclude that aid helps to equalize incomes in the world. Thus, the conclusions of our exercise will depend on the study and the specification within the study from which we take the coefficient of aid on growth.

For this exercise, we chose to concentrate on the conditional strand of aid-growth literature, since it has had the most influence on the donor community so far: Dollar and Levin (2004) find that the majority of donors have begun to focus their aid allocations on poor countries with better institutions. So, to take a first cut at the dynamic effects of aid on growth and international inequality, we conduct a simple exercise based on one of the most well-known studies that finds conditional effects of aid on growth - Collier and Dollar (2002), which uses an expanded dataset to test the Burnside-Dollar (2000) hypothesis of policy-conditional effect of aid on growth. We use the coefficients recorded by Collier and Dollar to examine the impact of aid on the resulting distribution of income across countries. As a baseline, we project GNI per capita in PPP terms, based on the historical geometric average growth rate over the 1992-2002 period to arrive at a hypothetical GNI per capita for each country in 2012. Then, we use the following estimates from Collier-Dollar, to deduct the growth impact of aid ${ }^{24}$ :

\footnotetext{
${ }^{23}$ For an extended recent review of aid-growth literature, see Clemens et al. (2004).

${ }^{24}$ This estimated equation is the first specification listed in Table 1 of Collier and Dollar (2002).
} 


$$
\begin{gathered}
\mathrm{G}_{\mathrm{i}}=\{\text { Set of variables not related to aid }\}-0.54 *\left(\mathrm{ODA}_{\mathrm{i}} / \mathrm{GDP}_{\mathrm{i}}\right)- \\
0.02 *\left(\mathrm{ODA}_{\mathrm{i}} / \mathrm{GDP}_{\mathrm{i}}\right)^{2}+0.31 *\left(\mathrm{CPIA}_{\mathrm{i}} * \mathrm{ODA}_{\mathrm{i}} / \mathrm{GDP}_{\mathrm{i}}\right)
\end{gathered}
$$

where $G_{i}$ is the growth rate of GNI per capita for country $i, O_{i} A_{i}$ is Official Development Assistance for country $i$, and CPIA $_{i}$ is the World Bank's Country Policy and Institutional Assessment index for country i.

We can then compare the resulting distribution of income across countries with the historical growth process as compared to a world in which aid does not impact growth rates according the empirical findings of Collier-Dollar. ${ }^{25}$ The resulting differences in the two distributions are displayed below. (Aid is measured in PPP terms for this exercise, so it is close to the "maximum scenario" described in the body of the paper.) The overall distributional effects are comparable to those obtained in the static case, except for deciles 2 and 3, where better policies generate larger growth benefits of aid.

\section{Figure A.1}

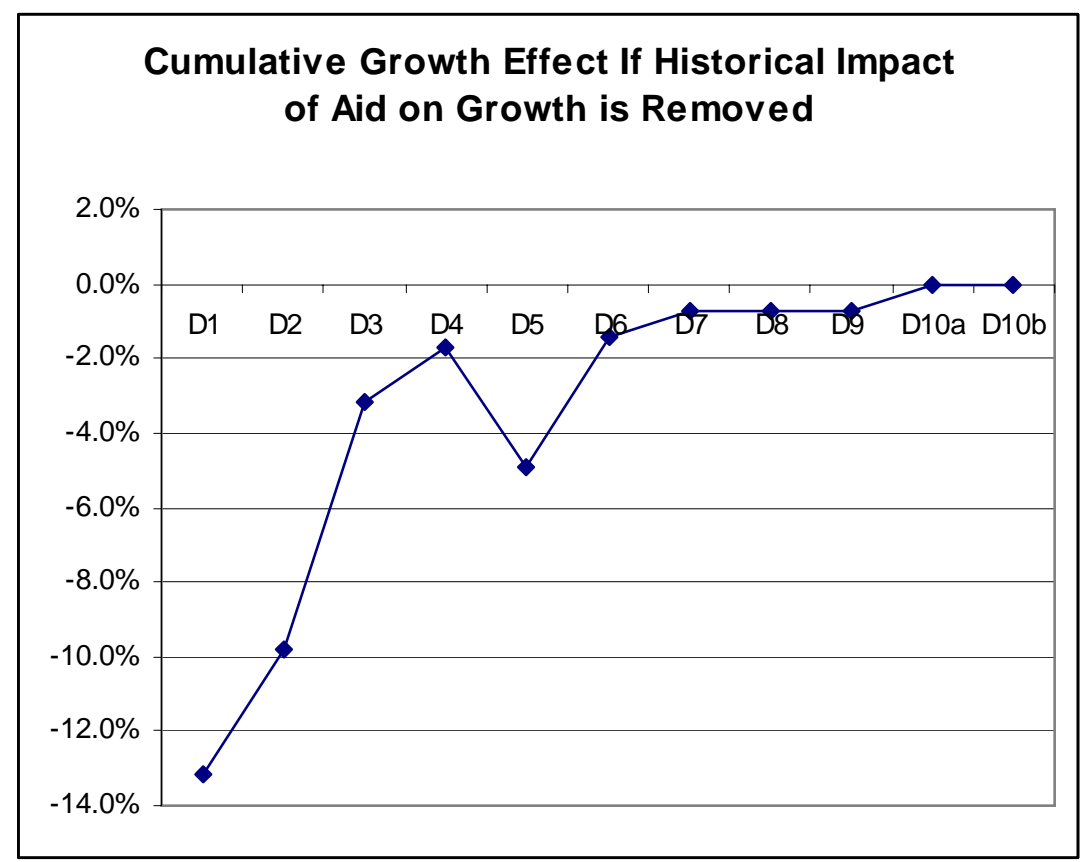

Source: Authors' calculations using data from World Bank (2004b). Three countries were removed from the sample used in the rest of the paper due to lack of PPP GNI data for the year 1992 (Cambodia, Slovenia and Samoa.)

\footnotetext{
${ }^{25}$ In the case of Mozambique, the estimated impact of aid on growth was adjusted as the values were particularly high.
} 


\section{Appendix 2: PPP Measurement of Welfare Gains from Aid}

\section{- A simple general equilibrium model of the effects of aid}

Consider the standard model of an economy that can produce two goods, a tradable good the quantity of which is denoted $q_{T}$, and a non-tradable good the volume of which is denoted $q_{N}$. On the consumption side, the quantities of tradable and non-tradable goods consumed are respectively, $c_{T}$ and $c_{N}$. Gross National Income, $Y$, results from the production of tradable and non-tradable goods as well as from transfers, A, from abroad.

$Y=q_{T}+\pi \cdot q_{N}+A$

Note that the tradable good is implicitly used here as the numeraire. This means in particular that the transfer A is logically expressed in terms of the tradable good - by definition, donors cannot transfer non-tradable goods. It is assumed that this economy does not save so that the budget constraint faced by the representative consumer is :

$$
c_{T}+\pi c_{N}=Y
$$

If the economy behaves in a competitive way, the quantity of tradable and non-tradable goods supplied by producers is obtained by maximizing the GNI in (1) under the production constraint. Let $q_{T}(\pi)$ and $q_{N}(\pi)$ be the corresponding supply functions. Likewise, the quantity demanded of the two goods is obtained by maximizing the utility of the representative consumer under the budget constraints (2). The corresponding demand functions are denoted $c_{T}(Y, \pi)$ and $c_{N}(Y, \pi)$.

The equilibrium of the economy is given by the demand-supply equalities on the markets for tradable and non-tradable goods:

$$
c_{T}(Y, \pi)=q_{T}(\pi)+A ; \quad c_{N}(Y, \pi)=q_{N}(\pi)
$$

Taken together these two equations determine the GNI, $Y$, and the price of the non-traded good, $\pi$. Of course, this system is equivalent to solving for the equilibrium on only one market - traded or non-traded goods - and taking into account the definition of GNI in $(1){ }^{26}$

In order to evaluate the effect of a change in the volume of aid, $A$, on the domestic economy, it is sufficient to differentiate the equilibrium system (3) with respect to $Y, \pi$ and A. Calculations reported in Bourguignon (2005) lead to the following result:

$$
\frac{\Delta \pi}{\Delta A} \cdot \frac{Y}{\pi}=\frac{1}{\psi_{T} \sigma_{Q}+\phi_{T} \sigma_{T}} ; \quad \frac{\Delta Y}{\Delta A}=1+\frac{\psi_{N}}{\psi_{T} \sigma_{Q}+\phi_{T} \sigma_{T}}
$$

\footnotetext{
${ }^{26}$ In other words, system (E) is strictly equivalent to : $c_{N}(Y, \pi)=q_{N}(\pi) ; Y=q_{T}(\pi)+\pi \cdot q_{N}(\pi)+A$
} 
where $\psi_{i}$ and $\varphi_{i}$ are respectively the share of good $i(=T$ or $N$ ) in total production (GDP) and in consumption (GNI) and $\sigma_{\mathrm{q}}$ and $\sigma_{\mathrm{c}}$ are respectively the elasticities of substitution between tradables and non-tradables on the production and the consumption side of the economy.

\section{- $\quad$ Measuring the welfare gain from aid}

What is the change in the welfare of the representative consumer of the domestic economy that is due to a change in aid? The answer to this question depends on the way welfare is being measured. The case considered here is consistent with current practice of measuring welfare by the PPP-corrected Gross National Income.

Following standard principles, let the Purchasing Power Parity index, $P$, be defined with reference to an international basket of goods $\left(\bar{a}_{T}, \bar{a}_{N}\right)$ and an international price system $(1, \bar{\pi})$ for tradable and non-tradable goods in the following way:

$$
P=\frac{\bar{a}_{T}+\bar{a}_{N} \bar{\pi}}{\bar{a}_{T}+\bar{a}_{N} \pi}
$$

In other words, $\mathrm{P}$ is the value of an international basket of goods at international prices relative to the value of the same basket at domestic prices. Without loss of generality, suppose that units are chosen in such a way that $\bar{a}_{T}+\bar{a}_{N} \bar{\pi}=\bar{\pi}=1$. Then, the welfare, $W$, of the representative agent in the domestic economy is defined as:

$W_{1}=\frac{Y}{\bar{a}_{T}+\bar{a}_{N} \pi}$

Differentiating this expression with respect to A yields :

$\frac{1}{W_{1}} \frac{\Delta W_{1}}{\Delta A}=\frac{1}{Y} \frac{\Delta Y}{\Delta A}-\frac{\bar{a}_{N} \pi}{\bar{a}_{T}+\bar{a}_{N} \pi} \cdot \frac{1}{\pi} \frac{\Delta \pi}{\Delta A}$

Substituting the differentials in (4) into the preceding expression then leads to:

$$
\frac{\Delta W_{1}}{W_{1}}=\frac{\Delta A}{Y} \cdot\left(1+\frac{\psi_{N}-b_{N}}{\psi_{T} \sigma_{Q}+\phi_{T} \sigma_{C}}\right)
$$

where $b_{N}=\bar{a}_{N} \pi / \bar{a}_{T}+\bar{a}_{N} \pi$ is the share of non-traded goods in the international basket of goods at domestic prices. 
On that expression, it can be seen that the relative welfare gain from aid is equal to the share of additional aid in GNI, both magnitudes being expressed in terms of the numeraire, say USD with a corrective term. The latter depends on elasticities of substitution in the domestic economy and the difference in the tradable/non-tradable good proportion between the domestic economy and the international basket used in the calculation of the PPP index. No correction is needed in an economy where the elasticity of substitution either for production or for consumption is infinite, or where the GDP share of tradable goods would be the same as in the international PPP basket when evaluated at domestic prices.

Accounting aid in PPP terms as done in the text is equivalent to ignoring that term, or to assume either that elasticities of substitution are very large or that consumption shares of tradables and non-tradables are not very different across countries. 
Appendix 3: Country Lists for Various Exercises

A3.1 Aid Exercise

A3.2 Trade Exercise 
A3.1 Aid simulations: full sample from WDI 2004 (159 observations)

\begin{tabular}{|c|c|c|c|}
\hline Albania & Dominica & Kuwait & Samoa \\
\hline Algeria & Dominican Republic & Kyrgyz Rep. & Saudi Arabia \\
\hline Angola & Ecuador & Laos & Senegal \\
\hline Antigua \& Barbuda & Egypt & Latvia & Sierra Leone \\
\hline Argentina & El Salvador & Lebanon & Singapore \\
\hline Armenia & Eritrea & Lesotho & Slovak Republic \\
\hline Australia & Estonia & Lithuania & Slovenia \\
\hline Austria & Ethiopia & Luxembourg & Solomon Islands \\
\hline Azerbaijan & Fiji & Madagascar & South Africa \\
\hline Bahrain & Finland & Malawi & Spain \\
\hline Bangladesh & France & Malaysia & Sri Lanka \\
\hline Barbados & FYROM-Macedonia & Mali & St. Kitts-Nevis \\
\hline Belarus & Gabon & Malta & St. Lucia \\
\hline Belgium & Gambia & Mauritania & St. Vincent \& Grenadines \\
\hline Belize & Georgia & Mauritius & Sudan \\
\hline Benin & Germany & Mexico & Swaziland \\
\hline Bolivia & Ghana & Moldova & Sweden \\
\hline Botswana & Greece & Mongolia & Switzerland \\
\hline Brazil & Grenada & Morocco & Syria \\
\hline Bulgaria & Guatemala & Mozambique & Tajikistan \\
\hline Burkina Faso & Guinea & Namibia & Tanzania \\
\hline Burundi & Guinea-Bissau & Nepal & Thailand \\
\hline Cambodia & Guyana & Netherlands & Togo \\
\hline Cameroon & Haiti & New Zealand & Tonga \\
\hline Canada & Honduras & Nicaragua & Trinidad \& Tobago \\
\hline Cape Verde & Hong Kong, China & Niger & Tunisia \\
\hline Central African Rep. & Hungary & Nigeria & Turkey \\
\hline Chad & Iceland & Norway & Turkmenistan \\
\hline Chile & India & Oman & Uganda \\
\hline China & Indonesia & Pakistan & Ukraine \\
\hline Colombia & Iran & Panama & United Kingdom \\
\hline Comoros & Ireland & Papua New Guinea & United States \\
\hline Congo Dem. Rep. (Zaire) & Israel & Paraguay & Uruguay \\
\hline Congo, Rep. & Italy & Peru & Uzbekistan \\
\hline Costa Rica & Jamaica & Philippines & Vanuatu \\
\hline Cote d'Ivoire & Japan & Poland & Venezuela \\
\hline Croatia & Jordan & Portugal & Viet Nam \\
\hline Czech Republic & Kazakhstan & Romania & Yemen \\
\hline Denmark & Kenya & Russia & Zambia \\
\hline Djibouti & Korea & Rwanda & \\
\hline
\end{tabular}




\section{A3.2 Trade Simulations}

The modeled regions are an aggregate of the 87 GTAP regions. The GTAP acronyms are in parenthesis. For details on the countries included in the GTAP aggregate regions see either the GTAP web site.

1 ANZ Australia and New Zealand (anz, nzl)

European Union-25 with EFTA (aut, bel, dnk, fin, fra, deu, gbr, grc, irl, ita, lux, nld, prt, esp, swe, cyp, cze, hun, mlt, pol, svk,

2 EUR svn, est, lva, ltu, che, xef, xer)

3 CAN Canada (can)

4 USA United States (usa)

5 JPN Japan (jpn)

6 HYA Korea and Taiwan, China (kor, twn)

7 HYC Hong Kong, China and Singapore (hkg, sgp)

8 ARG Argentina (arg)

9 BGD Bangladesh (bgd)

10 BRA Brazil (bra)

11 CHN China (chn)

12 IND India (ind)

13 IDN Indonesia (idn)

14 MEX Mexico (mex)

15 RUS Russia (rus)

16 ZAF South Africa (zaf)

17 THA Thailand (tha)

18 TUR Turkey (tur)

19 VNM Vietnam (vnm)

20 XSA Rest of South Asia (lka, xsa)

21 XEA Rest of East Asia and Pacific (mys, phl)

Rest of Latin America and the Caribbean (col, per, ven, xap, chl,

22 RLC ury, xsm, xca, xfa, xcb)

23 XEC Rest of Europe and Central Asia (alb, bgr, hrv, rom, xsu)

24 MNA Middle East and North Africa (xme, mar, tun, xnf)

Selected SSA countries (bwa, mwi, moz, tza, zmb, zwe, mdg,

25 SSS uga)

26 XSS Rest of Sub-Saharan Africa (xsc, xsd, xss)

27 ROW Rest of the World (xoc, xea, xse, xna)

Source: van der Mensbrugghe (2005). 